\section{High-temperature Tolerance of Heritage River Birch Roots Decreased by Pot-In-Pot Production Systems}

\author{
John M. Ruter ${ }^{1}$ \\ Department of Horticulture, Coastal Plain Experiment Station, University of \\ Georgia, Tifton, GA 31793-0748 \\ Additional index words. Betula nigra, electrolyte leakage, heat tolerance, membrane \\ thermostability
}

\begin{abstract}
Membrane thermostability of Heritage river birch (Betula nigra L. Heritage) was measured by electrolyte leakage from excised roots of plants grown in pot-in-pot (PIP) and conventional aboveground production systems (CPS). The predicted critical midpoint temperature $\left(T_{m}\right)$ for a 30-min exposure was $54.6 \pm 0.2^{\circ} \mathrm{C}$ for PIP and 56.2 $\pm 0.6^{\circ} \mathrm{C}$ for $\mathrm{CPS}$ plants. Plants grown PIP had a steeper slope through the predicted $T_{m}$, suggesting a decreased tolerance to high root-zone temperatures in relation to plants grown aboveground. Since the root systems of Heritage river birch grown PIP are damaged at lower temperatures than plants grown aboveground, growers should prevent exposure of root systems to high temperatures during postproduction handling of plants grown PIP.
\end{abstract}

Plants grown in a pot-in-pot (PIP) production system generally have more white root tips on the exterior of the rootball at the container-substrate interface than plants grown in conventional aboveground production systems (CPS) (Parkerson, 1990; Ruter, 1993). Rootzone temperatures are generally highest in the outer $2.5 \mathrm{~cm}$ of the rootball (Martin and Ingram, 1988). Since a significant portion of the roots are concentrated in the area of higher rootzone temperatures, PIP-grown plants are more susceptible to damage by high temperatures during postproduction handling than are CPSproduced plants. This study was conducted to determine if roots of Heritage river birch grown PIP were more susceptible to lethal hightemperature damage than plants grown CPS.

\section{Materials and Methods}

Plants were grown outdoors at the Univ. of Georgia Coastal Plain Experiment Station. Uniform liners of Heritage river birch were transplanted from 2.8 - $\mathrm{L}$ containers to $26-\mathrm{L}$ containers (The Lerio Corp., Valdosta, Ga.) on 5 Apr. 1994. Potting substrate was 8 milled pine bark : 1 sand $(\mathrm{v} / \mathrm{v})$ amended with Micromax (O.M. Scott \& Son, Marysville, Ohio) at $0.9 \mathrm{~kg} \cdot \mathrm{m}^{-3}$ and dolomitic limestone at $3.0 \mathrm{~kg} \cdot \mathrm{m}^{-3}$. Osmocote $16 \mathrm{~N}-3.1 \mathrm{P}-12 \mathrm{~K}$ (O.M. Scott \& Son) was topdressed at $250 \mathrm{~g} / \mathrm{con}$ tainer. Plants were grown with spacing between plants of $1.5 \times 3.0 \mathrm{~m}$ to prevent shading of adjacent containers by canopy foliage.

Holder pots were placed in the ground with $2.5 \mathrm{~cm}$ exposed above grade. Conventional

Received for publication 11 Dec. 1995. Accepted for publication 7 May 1996. The cost of publishing this paper was defrayed in part by the payment of page charges. Under postal regulations, this paper therefore must be hereby marked advertisement solely to indicate this fact.

${ }^{1}$ Associate Professor. aboveground pots were placed on bare soil. All pots were fully rotated monthly to prevent elongation of roots passing through the drain holes into the surrounding soil. Plants were irrigated daily with $160^{\circ}$, low-volume spot spitters (Roberts Irrigation, San Marcos, Calif.) at $3.8 \mathrm{~L}$ per container. Root systems were prepared for analysis on 16 Aug. 1994.

Root substrate temperatures were recorded system (CPS) or pot-in-pot (PIP) system. Means \pm 1 SE. daily (0900 to $1700 \mathrm{HR}$ ) for 2 weeks before harvest (Table 1) using copper-constantan thermocouples connected to a $21 \times$ micrologger with a AM-32 multiplexer (Campbell Scientific, Logan, Utah). Thermocouples were positioned in the substrate $0.15 \mathrm{~m}$ below the surface of the substrate on the north, east, south, and west solar quadrants, $0.025 \mathrm{~m}$ inside the container wall.

Electrolyte leakage procedures for determining the $T_{m}$ for roots were performed as described by Ingram and Buchanan (1984). Excised portions (0.5-g samples) taken from the terminal 15 to $20 \mathrm{~cm}$ of actively growing roots occurring within $5 \mathrm{~cm}$ of the container wall were placed in test tubes and exposed for $30 \mathrm{~min}$ to temperatures ranging from 30 to 60 ${ }^{\circ} \mathrm{C}$ in a thermostatically controlled circulating water bath. After removal, roots were cut in 10 -mm segments and returned to the test tubes with $20 \mathrm{~mL}$ of deionized water before ice bath incubation for $24 \mathrm{~h}$ and initial conductivity measurement (\#1481-90; Cole-Palmer, Chicago). Final solution conductivity was measured on samples after autoclaving and incubation in ice for $24 \mathrm{~h}$. Critical midpoint temperatures $\left(\mathrm{T}_{\mathrm{m}}\right)$ were determined by fitting a sigmoidal response curve fitted to electrolyte leakage data across temperature treatments using a least-squares approach (Ingram and Buchanan, 1984). A sigmoidal equation: $L_{e}=$ $\left[(\mathrm{x}-\mathrm{z}) /\left(1+\exp \left[-\mathrm{K}\left(\mathrm{T}-\mathrm{T}_{\mathrm{m}}\right]\right)\right]+\mathrm{z}\right.$ was used to fit the data, where $\mathrm{L}_{\mathrm{e}}$ was the percent leakage, $\mathrm{z}=$ baseline level of electrolyte leakage, $\mathrm{x}=$ maximum level of electrolyte leakage, $\mathrm{T}_{\mathrm{m}}=$

Table 1. Mean root substrate temperatures (0900 to $1700 \mathrm{HR}$ ) for 1-14 Aug. 1994 in the north, east, south, and west solar quadrants of Betula nigra Heritage grown using a conventional aboveground production

\begin{tabular}{lcccr}
\hline \multirow{2}{*}{$\begin{array}{l}\text { Production } \\
\text { system }\end{array}$} & \multicolumn{4}{c}{ Root substrate temp $\left({ }^{\circ} \mathrm{C}\right)$} \\
\cline { 2 - 5 } & North & East & South & West \\
\cline { 2 - 5 } CPS & $33.1 \pm 1.5$ & $36.9 \pm 1.4$ & $37.9 \pm 1.9$ & $35.6 \pm 2.5$ \\
PIP & $31.4 \pm 0.9$ & $32.2 \pm 0.9$ & $32.6 \pm 1.3$ & $31.5 \pm 1.4$ \\
\hline
\end{tabular}

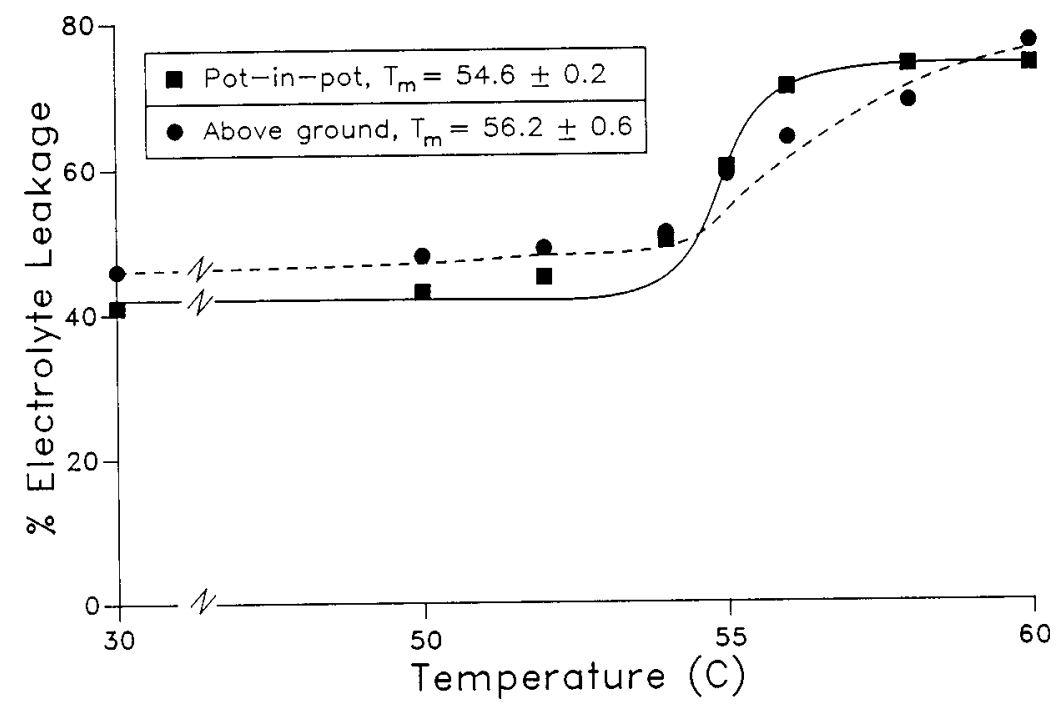

Fig. 1. Predicted response curves of percent electrolyte leakage from excised roots of Betula nigra Heritage after a 30-min exposure to solution temperatures ranging from 30 to $60{ }^{\circ} \mathrm{C}$ as a function of production system (pot-in-pot vs. conventional aboveground). The $\mathrm{T}_{\mathrm{m}}$ (mean $\pm 1 \mathrm{sE}, \mathrm{n}=8$ ) was estimated by fitting sigmoidal response curves to electrolyte leakage data using a least-squares approach. 
predicted critical midpoint temperature, $\mathrm{k}=$ slope of the predicted response curve at $T_{m}$, and $\mathrm{T}=$ bathing solution temperature.

\section{Results and Discussion}

The relationship between electrolyte leakage and temperature was correctly predicted to be sigmoidal for each treatment (Fig. 1). The $\mathrm{T}_{\mathrm{m}}$ for excised roots of Heritage river birch grown in the CPS were $\approx 1.5^{\circ} \mathrm{C}$ higher $(56.2 \pm$ $\left.0.6^{\circ} \mathrm{C}\right)$ than roots grown $\operatorname{PIP}\left(54.6 \pm 0.2^{\circ} \mathrm{C}\right)$.

The narrower response curve of excised roots from the PIP production system compared to CPS was reflected in their $\mathrm{k}$ values $(\mathrm{PIP}=1.81 \pm 0.40, \mathrm{CPS}=0.66 \pm 0.23)$. Excised roots of Magnolia grandiflora Hort. 'St. Mary' had a higher $\mathrm{T}_{\mathrm{m}}$ and lower $\mathrm{k}$ values when root systems were pretreated at 35 and $42{ }^{\circ} \mathrm{C}$ than at $28^{\circ} \mathrm{C}$ for $6 \mathrm{~h}$ daily for 8 weeks
(Martin et al., 1991). A higher k value indicates a narrower temperature response range for direct membrane injury (Donovan et al., 1990; Martin et al., 1991). Because the $\mathrm{T}_{\mathrm{m}}$ was higher and the $\mathrm{k}$ value was lower for excised roots from CPS plants, I conclude that higher root-zone temperatures would be required to cause root death due to membrane disruption and that CPS plants would tolerate a wider range of high root-zone temperatures than plants grown PIP.

Due to the sensitivity of Heritage river birch to postproduction handling problems, such as exposure to high root-zone temperatures, growers should attempt to minimize exposure of containers to direct solar insolation or harvest plants under lower solar radiation conditions. Pot-in-pot production remains a viable production alternative as long as plants receive proper postproduction care.

\section{Literature Cited}

Donovan, L.A., K.W. McLeod, and K.L. Grant. 1990. Direct heat injury of roots of woody swamp species. J. Therm. Biol. 15:245-249.

Ingram, D.L. and D.W. Buchanan. 1984. Lethal high temperatures for roots of three citrus rootstocks. J. Amer. Soc. Hort. Sci. 109:189-193.

Martin, C.A. and D.L. Ingram. 1988. Temperature dynamics in black poly containers. Proc. Southern Nurseryman's Res. Conf. 33:71-74.

Martin, C.A., D.L. Ingram, and M.A. Jenks. 1991. Response of southern magnolia to supraoptimal root-zone temperatures. J. Therm. Biol. 16:281285.

Parkerson, C.H. 1990. P \& P: A new field-type nursery operation. Proc. Intl. Plant Prop. Soc. 40:417-419.

Ruter, J.M. 1993. Growth and landscape performance of three landscape plants produced in conventional and pot-in-pot production systems. J. Environ. Hort. 11:124-127. 